\title{
NOTAS \\ SOBRE ECOCRÍTICA \\ Y POESÍA CHILENA
}

\section{NOTES ON ECOCRITICISM AND CHILEAN POETRY}

\section{MAURICIO OSTRIA GONZÁLEZ²}

\section{RESUMEN}

Se examinan algunas prácticas poéticas chilenas, caracterizadas por presentar visiones profundas de los sujetos humanos y la naturaleza. Se indaga en ellos tanto las relaciones de los sujetos con su medio y la presencia de una conciencia ecológica activa, como la plasmación discursiva de un imaginario vinculado a esa conciencia relacional; la plasmación de vivencias de profunda integración del ser humano con el cosmos. Se indaga tanto los referentes ambientales como la articulación de elementos de lá naturaleza en tanto expresión de los sujetos textuales.

Palabras clave: Ecocrítica, ecopoesía, literatura chilena, naturaleza/cultura.

\section{ABSTRACT}

Certain Chilean poetics practices are examined, which present profound visions of human subjects and of nature. The inquiry focuses on both the subjects relations with their environment, and the presence of an active ecological awareness, as well as the literary concretion of an imagery linked to that relational awareness: the concretion of experiences of a profound integration of the human being with the cosmos. Environmental referents and the articulation of natural elements as expression of textual subjects are approached within the frame of globalization processes and the defense of regional cultural values.

Keywords: Ecocriticism, ecopoetry, Chilean literature, nature/culture.

Recibido: 05.06.2010. Aprobado: 14.09.2010.
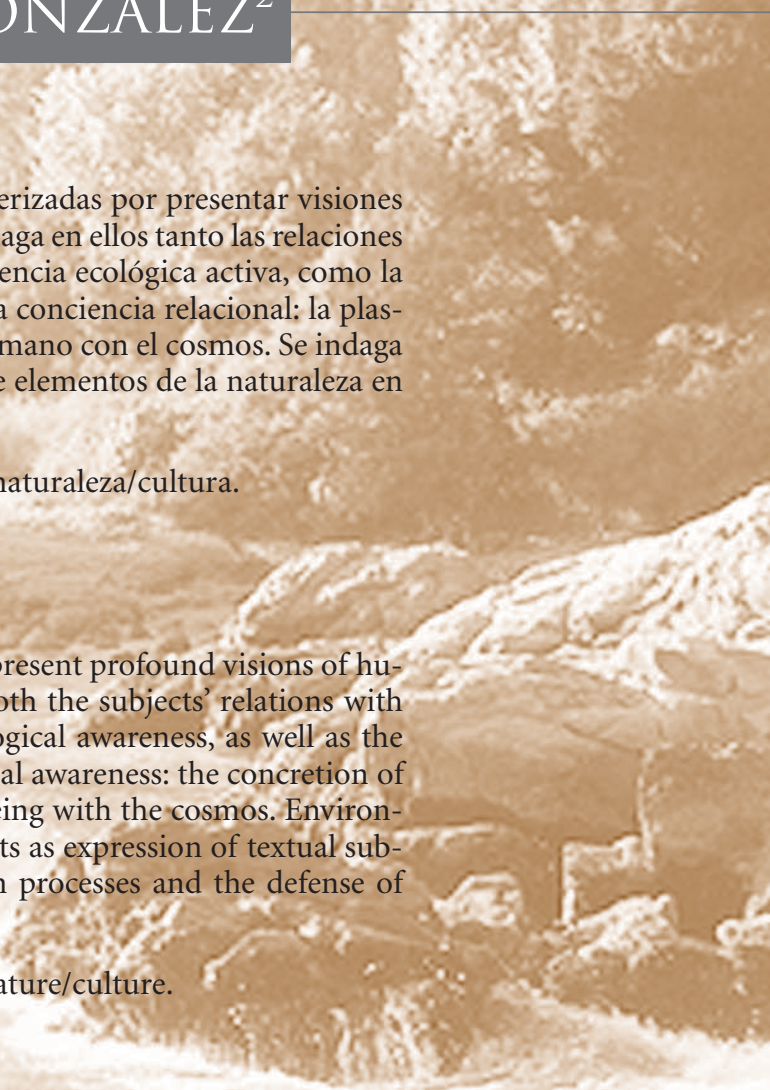

ser humano con el mundo (el de las cosas y el de la subjetividad) no puede estar ajena a la problemática ambiental. En efecto, las preocupaciones ecológicas pueden rastrearse tanto en importantes textos (narraciones, poemas, ensayos) como en diversos trabajos críticos y hasta en algunas obras de teoría literaria y semiótica. Así, en los últimos años ha surgido, en el seno de la crítica anglosajona, la llamada Ecocrítica o ecocriticismo (ecocriticism) $)^{3}$, que se define como "el estudio de las relaciones entre la literatura y el medio ambiente" (Glotfelty y Fromm 1996: xiii) y que, en general, explora la visión de la naturaleza en obras que manifiesten una preocupación por denunciar el deterioro medioambiental o por representar como un valor la relación del hombre con su medio natural, su lugar, su oikos. La ecocrítica o crítica ecológica procura integrar las producciones textuales a un sistema mayor que las tradicionales series literarias, culturales e históricas, desplazando la obra hacia un nuevo entorno valórico ${ }^{4}$, eco-céntrico, que inserta la obra y al autor en las matrices que la/lo sustentan. Se trata, en general, de asumir una perspectiva que recupere la conexión entre la naturaleza y la cultura y que haga visible la materialidad de las interrelaciones e integraciones de los soportes y elementos que aseguran la vida básica del planeta. En ese enfoque, el nexo entre literatura y naturaleza representa la unión primordial del hombre con su entorno natural. Se trata de una conexión que permita conjugar el mundo exterior, mítico y sagrado de la naturaleza con la subjetividad y el mundo social. Porque, como acertadamente, advierte Binns: "el trastorno ecológico no deja de ser un trastorno lingüístico y literario más profundo. Grandes símbolos aparentemente intemporales (el mar, el río, la lluvia, el aire, el bosque, la tierra) se están contaminando y agotando, como discursos difícilmente renovables, al ritmo de la depredación planetaria" (2004). Por otra parte, es cada vez más creciente -y esto también se vincula íntimamente con el fenómeno literario-la comprensión de la subjetividad como un complejo bio-socio-cultural y de la naturaleza como una categoría cada vez más 'humanizada' (ya sea como capital sim-

\footnotetext{
${ }^{3}$ El término proviene del ensayo de William Rueckert titulado "Literature and Ecology: An Experiment in Ecocriticism" (1989). Ver Referencias.

${ }^{4}$ Esta valoración, como señala Donald Worster, conlleva un fuerte carácter ético: "Estamos enfrentando hoy en día una crisis global no por cómo funciona el ecosistema, sino por cómo funciona nuestro sistema ético. Franquear esta crisis requiere entender nuestro impacto sobre la naturaleza [...] pero aun más, requiere la comprensión de aquellos sistemas éticos y el uso del entendimiento para reformarlos. Los historiadores, los académicos de la literatura, antropólogos y filósofos, no pueden hacer la reforma, pero pueden ayudar con la comprensión" (Glotfelty y Fromm 1996: xxi).
} 
bólico en relaciones de poder o como una noción enfocada en la interacción entre lo humano y lo no-humano, en lugar de su oposición $)^{5}$.

La crítica literaria ha cumplido históricamente con la función primordial de ser un intermediario o mediador entre el texto y su receptor. Sin embargo, desde un enfoque heredado de las utopías sociales y el humanismo verde, la ecocrítica busca mediar entre los autores, sus textos, la biosfera y el lector, estableciendo críticamente las conexiones y puentes de enlace entre el sujeto y el entorno. Así, Glen Love sostiene la necesidad de revertir el predominio de la conciencia antropocéntrica o ego-conciencia, como él la llama, por el de la conciencia ecológica o eco-conciencia (1996: 233). Se trata de evolucionar desde una conciencia especular y narcisista a una conciencia habitada por la real identificación del hombre con su matriz natural. Refiriéndose, específicamente, al papel de la literatura y la crítica literaria, Love señala: "Hoy en día, la función más importante de la literatura es redireccionar la conciencia humana hacia una consideración total de su importancia en un mundo natural amenazado [...] reconociendo la supremacía de la naturaleza, y la necesidad de una nueva ética y estética. Y agrega: [tenemos la] esperanza de recobrar el perdido rol social de la crítica literaria" (1996: 237-8) .

Desde la filosofía y la semiótica, se han hecho oír voces como las de Félix Guattari, Edgar Morin y Gianni Vattimo. El primero, en su ensayo Las tres ecologías, amplía el concepto de ecología a la "articulación ético-política [...] entre los tres registros ecológicos, el del medio ambiente, el de las relaciones sociales y el de la subjetividad humana" (1996: 7); reconoce la "paradoja lancinante: por un lado, el desarrollo continuo de nuevos medios técnicocientíficos, susceptibles potencialmente de resolver las problemáticas ecológicas dominantes y el reequilibrio de las actividades socialmente útiles sobre la superficie del planeta y, por otro, la incapacidad de las fuerzas sociales organizadas y de las formaciones subjetivas constituidas de ampararse de esos medios para hacerlos operativos" (1996: 14). Morin se refiere a la aparición de la conciencia ecológica, gracias a la cual se produce "1) la reintegración de nuestro medio ambiente en nuestra conciencia antropológica y social, 2) la resurrección ecosistémica de la idea de naturaleza, 3) la decisiva aportación de la biosfera a nuestra conciencia planetaria". Morin afirma: "Algunos han pensado definir al hombre por la disyunción y oposición a la naturaleza; otros han pensado definirlo por integración en la naturaleza.

\footnotetext{
${ }^{5}$ Cf. Marcone 2007.

${ }^{6}$ En la misma línea de pensamiento, véanse los trabajos de Ruecker 1996 y Warwick 1990, Worster 2000, Buell 1995, Bate 2000.
} 


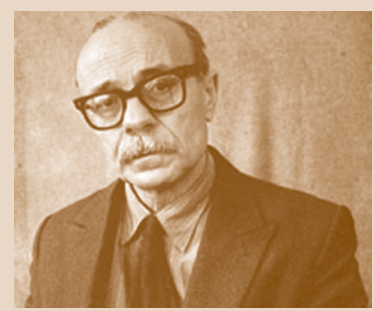

E. Sábato

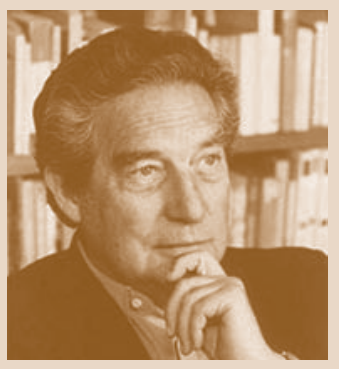

O. Paz

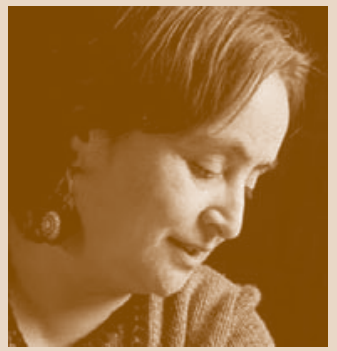

R. Muñoz

Ahora bien, debemos definirnos a la vez por la inserción mutua y por nuestra distinción con respecto a la naturaleza. Vivimos esta paradójica situación". Y concluye: "Cada vez más, todo devenir local está en inter-retro-acción en y con el contexto planetario global. Pero, al mismo tiempo que se han multiplicado nuevas solidaridades, se han multiplicado igualmente los antagonismos y los avasallamientos. En este sentido, estamos aún en 'la edad de hierro de la era planetaria"' (1996: 122-16). Vattimo, por su parte, insiste en la necesidad del diálogo intercultural, del reconocimiento de las diferencias y denuncia que escindido de la naturaleza y la espiritualidad que la habita, el hombre moderno no es otra cosa que un consumidor consumido y consumado, habitante de grandes ciudades manejado por los medios de comunicación y la publicidad (1990). En el mismo sentido, encontramos, en el pensamiento latinoamericano, pronunciamientos de Ernesto Sábato (2000), Octavio Paz (1999) o Eduardo Galeano (1994).

Se desprende del discurso de los pensadores que la actual crisis ambiental es fundamentalmente una crisis civilizatoria y que el uso, e incluso la constitución de los ecosistemas, está pautado culturalmente; de ahí que una buena parte de las causas de los desequilibrios ambientales deba ser identificada en los procesos sociales. Por otra parte, queda claro que el pensamiento ambiental es un pensar perfectible, en construcción, abierto a la utopía a la vez que crítico de las experiencias históricas.

En poesía, diversos escritores latinoamericanos han asumido una postura militante en cuanto a denunciar y resistir las políticas y los atentados en contra del medio ambiente. Es, por ejemplo, el caso de Ernesto Cardenal, Pablo Antonio Cuadra, Roque Dalton, Mario Benedetti, Homero Aridjis, José Emilio Pacheco, Giconda Belli, Roberto Juarroz.

2. Chile no ha sido una excepción al respecto. Así, narradores como Luis Sepúlveda, sobre todo en El viejo que leía novelas de amor y Mundo del fin del mundo, o Darío Oses en su novela de anticipación 2010. Chile en llamas, se han esforzado por evidenciar los peligros de una falta de conciencia ecológica. En poesía, en tanto, Nicanor Parra, particularmente a partir de su ecopoesía ${ }^{7}$, Óscar Hahn, Gonzalo Millán ${ }^{8}$, Raúl Zurita, Juan Pablo Riveros, Clemente Riedemann, Sonia Caicheo, Rosabety Muñoz ${ }^{9}$, entre muchos otros, se han

\footnotetext{
${ }^{7}$ Es cierto que se puede rastrear la preocupación de Parra por el medio ambiente en poemas anteriores. Cf. Carrasco 1990: 233.

${ }^{8}$ Véase al respecto, el excelente trabajo de Galindo 2004.

${ }^{9}$ Véase, Ariz 2005.
} 
convertido en conciencias denunciadoras de la destrucción del medio ambiente.

He aquí, algunos antipoemas ecológicos parrianos:

¿Qué le dijo Milton Friedman

a los pobrecitos alacalufes?

-A comprar a comprar

quel mundo se vacabar!

EXPLOSIÓN DEMOGRÁFICA

SAQUEO DE LA NATURALEZA

COLAPSO DEL MEDIO AMBIENTE

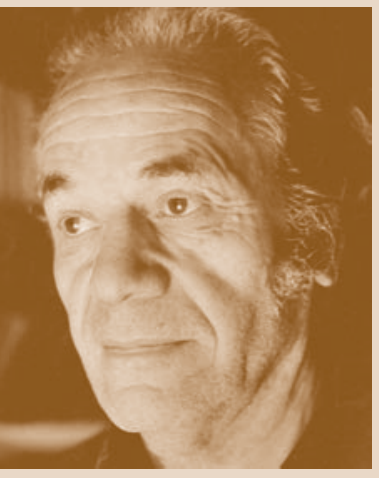

vicios de la sociedad de consumo

N. Parra

que no podemos seguir tolerando:

¡hay que cambiarlo todo de raíz!

Ya no pedimos pan

techo

ni abrigo

nos conformamos con un poco de

aire

¡EXCELENCIA!

Recuerdos de infancia:

los árboles aún no tenían forma de muebles

$\mathrm{y}$ los pollos circulaban crudos $\mathrm{x}$ el paisaje.

Buenas Noticias:

la tierra se recupera en un millón

de años

Somos nosotros los que desaparecemos.

ESTIMADOS ALUMNOS

adiós estimados alumnos

y ahora a defender los últimos cisnes de cuello

negro

que van quedando en este país

a patadas

a combos/

a lo que venga:

la poesía nos dará las gracias... 
Puro Chile es tu cielo azulado chiste ecológico puras brisas te cruzan también ¿vai a seguir? (1983: 151-163).

Como se puede apreciar, los recursos antipoéticos son los mismos: heterogeneidad discursiva, empleo de procedimientos propios de la lengua oral y de la escritura popular urbana; ruptura de discursos canónicos, ironía y parodia. Sin embargo, esta vez, el hablante no es simplemente el francotirador de la antipoesía, los artefactos y los chistes, sino una especie de profeta, defensor de la Tierra, que denuncia su destrucción y la del ser humano. Ahora es el "poeta de la tribu", que se siente parte de una comunidad en peligro.

Yo veo al poeta ahora como fabricante de pancartas. Ponte tú, un tipo de pancarta: 'El error consistió en creer que la tierra era nuestra, cuando la verdad de las cosas es que nosotros somos de la tierra'. Yo creo que vale la pena enunciar este pensamiento (en Morales 1992: 119).

Como acota sagazmente Iván Carrasco: "la antipoesía ecológica transgredió otras formas de poesía; la antipoesía se contradice a sí misma como parte de su proceso de autocorrección" (1990: 236).

La denuncia ecológica de Juan Pablo Riveros, en De la tierra sin fuegos $(1986)^{10}$, se funde con la destrucción de los indígenas y sus culturas:

el Kolliot ocupó

las tierras que Taiyín, por encargo de Temáuquel,

distribuyó entre nuestras treinta y nueve estirpes:

(...) El Kolliot

cercó nuestros cielos y estrellas.

Ató nuestros Haruwen a sus motivos de lucro.

Cazó, no, destruyó

a nuestros guanacos. Blanqueó de ovejas el Sur.

Se nos persiguió y asesinó. Envenenaron

al guanaco blanco para diezmarnos.

Enviaron ropas infectas para que con-

trajéramos enfermedades. Hubo

una gran guerra con el blanco. Y fuimos

expulsados de nuestros Haruwen, de nuestros

Sho' on milenarios. (80);

${ }^{10}$ Véase Ostria 1992. 
Ushuaia: comienzo de la decadencia yámana.

Antes ignorada

la tisis, el sarampión.

Cosa rara, la muerte prematura...

'USHUAIA: cementerio de nuestra tribu',

decían los yámanas (120);

ya no hay ceremonias

ni mímicas

ni cantos [142].

Por vía imaginativa y documental, se va construyendo, por una parte, la

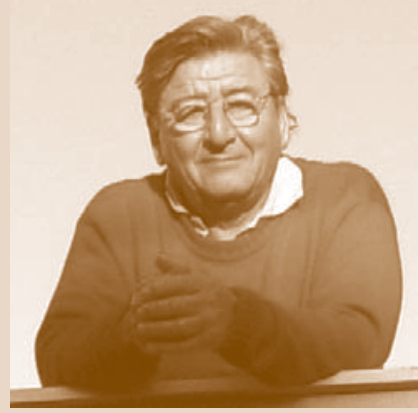
visión de los vencidos, el recuerdo y la elegía, sin lamentos, sin tristeza, mas honda, convincente -"no es ona la tristeza"- (81). Donde la acumulación de formas pretéritas conclusas, clausuradas sugieren el vendaval de cambios maléficos que sustituye al hieratismo religioso, inmutable, del ya no más presente continuo. Por otra, como el antiguo cronista, el hablante formula su 'protestación' sobre la historia: "me he atenido a la más estricta verdad" (81); como los cronistas acumula testimonios y llega a identificarse con Martín Gusinde, el sacerdote y antropólogo austriaco, implacable denunciador de la destrucción de los fueguinos:

Ninguna fiera se ha comportado

de manera tan cruel como lo han hecho

los blancos contra los indios indefensos [68].

¿Dónde están onas? ¿Dónde

yagán manso, leve alacalufe?

¿Dónde hombres diligentes,

mujer tenaz?

¿No cogeréis más, gacela, dulce

yagana, moluscos a la orilla del mar?

¿Dónde está tu pueblo, Temáuquel?

¿Dónde tus marinos Watauinewa?

Pregúntaselo al Kolliot

Murieron de Occidente $(156)^{11}$.

El trabajo de manipulación textual (recorte, montaje, fusión, cita, paráfrasis, glosa, etc.) que el autor emplea para recrear modos de sentir y de

${ }^{11}$ Las páginas corresponden a la primera edición (Riveros 1986). 
decir de una cultura extinta, posibilita el rescate y la contemplación, por vía ficcional, claro, de valiosas y sabias formas de vida, fuego intacto conservado en las palabras salvadas de la muerte. En medio de la hecatombe, el poeta descifra signos sobrevivientes, restos del naufragio, traduce, interpreta, adivina, intuye los misterios de las antiguas culturas, se identifica con sus hablantes y, escarbando textos y sobrepasando mediaciones, logra una visión convincente, conmovedora -llena de fuego-del otro que ya no podemos ser, aunque la tierra yerta no pueda devolvernos, jamás, el eco de su risa.

Pero es, posiblemente, en la producción literaria de los escritores de origen mapuche donde se pueden encontrar los testimonios más persuasivos y la resistencia más entrañable contra la agresividad depredadora de la globalización, así como la defensa cerrada de tradiciones y territorios amenazados frente al avance del llamado progreso. Véanse estos versos de Leonel Lienlaf:

\author{
La vida del árbol \\ invadió mi vida \\ comencé a sentirme árbol \\ y entendí su tristeza. \\ Empecé a llorar por mis hojas, \\ mis raíces, \\ mientras un ave \\ se dormía en mis ramas \\ esperando que el viento \\ dispersara sus alas. \\ Yo me sentía árbol \\ porque el árbol era mi vida \\ (“Transformación”, Lienlaf, 1989: 99).
}

En ellos se expresa una dinámica que parte del árbol (no del sujeto) y en que, por tanto, es el árbol el elemento activo ("La vida del árbol / invadió mi vida"). Se llega así a la identificación total con la vida del árbol, de modo que ya no son más dos (el yo y el árbol) sino uno solo: un solo ser en que habita la misma vida, los mismos sentimientos, las mismas sensaciones e, incluso, el mismo entendimiento. El proceso de fusión se describe escuetamente, en un decir sin adjetivos ni construcciones complejas, sugiriendo la oralidad del mapudungún y de la cultura mapuche. Al principio, el proceso es puntual y concluso (el discurso se caracteriza por el uso del pretérito indefinido); luego se hace continuo y duradero: las frases se construyen con formas de gerundio y pretérito imperfecto (indicativo y subjuntivo): 
Y estos otros, en que la agresión de los huincas afecta tanto a los seres humanos (corro a ver a mi gente / a mi sangre / pero ya están tendidos sobre el suelo") como a la tierra ("hiriendo de muerte la tierra") y en que el dolor del "corazón dividido" se prolonga por la historia en un proceso de muerte que aún continúa y que sorprende al sujeto perdido entre las 'palabras-lágrimas':

\section{Bajan gritando}

ellos sobre los campos

silbando por los esteros

corro a ver a mi gente

a mi sangre

pero ya están tendidos

sobre el suelo

sobre ellos pasan los huincas

hiriendo de muerte la tierra

dividiendo mi corazón

Entré en busca de mi calor

A mi casa ardiendo

Brotó el estero de mis lágrimas lloviendo sobre mis pies

¿Ustedes entienden mis lágrimas?

Escuchen al aire explicarlas

Están pasando los años,

Están pasando los nidos sobre el fuego

Está pasando la tierra

Y ya me estoy perdiendo entre las palabras

Escuchen hablar a mis lágrimas.

(“Bajan gritando ellos sobre los campos”, Lienlaf s.f. )

3. Por diversos caminos, la poesía chilena contemporánea (la antipoesía, la poesía de los ochenta, la poesía etnocultural, de origen mapuche) asume la defensa de la tierra, irguiéndose como una manifestación de resistencia y denuncia frente a la depredación de que es objeto el planeta a causa de la contaminación y sobreexplotación ejercida, fundamentalmente, por las grandes potencias industriales.

La escritura poética chilena, la escritura poética en general, es un permanente testimonio de que el ser humano y su entorno natural y social constituyen una unidad compleja e inseparable, un conjunto de relaciones (oposiciones, interdependencias, solidaridades), necesarias y dinámicas, presen-

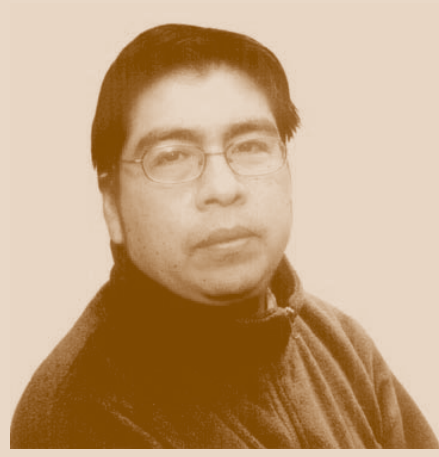

L. Lienlaf 
tes en cada momento y en cada acto singular y que lejos de ser los dueños, los dominadores del planeta, somos una mínima manifestación de su poderío. Como escribió el Jefe Seattle: “Todo va enlazado. Todo lo que ocurra a la Tierra les ocurrirá a los hijos de la Tierra. El hombre no tejió la trama de la vida, el sólo es un hilo. Lo que hace con la trama se lo hace a sí mismo".

\section{REFERENCIAS}

Ariz, Jenny. 2005. "La loba y la luciérnaga. La heterogeneidad del discurso poético de Rsabetty Muñoz y Sonia Caicheo", Acta Literaria, 31: 63-82.

Bate, Jonathan. 2000. The Song of the Earth. Londres: Picador.

Binns, Niall (coord.). 2004. "Presentación", Anales de Literatura Hispanoamericana, 33: 11-13.

Glotfelty, Cheryll, y Harold Fromm. 1996. The Ecocriticism Reader: Landmarks in Literary Ecology. Athens and London: University of Georgia Press.

Buell, Lawrence. 1995. The Environmental Imagination: Thoreau, Nature Writing, and the Formation of American Culture. Cambridge, MA.: The Belknap Press.

Carrasco M., Iván. 1990. Nicanor Parra: la escritura antipoética. Santiago: Universitaria.

Galeano, Eduardo. 1994. Úselo y tírelo. El mundo del fin del milenio visto desde una ecología latinoamericana. Buenos Aires: Planeta.

Galindo, Óscar. 2004. “Distopía y apocalipsis en la poesía de Óscar Hahn y Gonzalo Millán", Anales de Literatura Hispanoamericana, 33: 65-76.

Guattari, Félix. 1996. Las tres ecologías. Valencia: T. P. Ripoll (trad. J. Vásquez Pérez y U. Larraceleta).

Lienlaf, Leonel. 1989. Se ha despertado el ave de mi corazón. Santiago: Editorial Universitaria.

Lienlaf, Leonel. s/f. "Bajan gritando ellos sobre los campos", en Biblioteca Virtual Miguel de Cervantes, Poesía contemporánea. Disponible en: http:// www.cervantesvirtual.com/portal/poesia/lienlaf/textos.shtml [Consulta: 08.05.10].

Love, Glen. 1996. "Revaluing Nature, en Glotfelty, Cheryll y Fromm, Harold. The ecocriticism reader: Landmarks in literary ecology. Athens / Georgia: University of Georgia Press.

Marcone, Jorge. 2007. "El misterio de las primeras confluencias. Crítica ecológica y literatura latinoamericana de los '50”. Disponible en: http://www.stoa.org/ $\mathrm{kflc2} /$ papers.php?sort=title\&first_letter=all\&cf=4 [Consulta: 06.04.10].

Morales T., Leonidas. 1992. Conversaciones con Nicanor Parra. Santiago: Universitaria.

Morin, Edgar. 1996. “El pensamiento ecologizado", Gazeta de Antropología, 12: 12-16. 
Ostria González, Mauricio. 1992. “De la Tierra sin fuegos de Juan Pablo Riveros. Los fuegos de la escritura", Acta Literaria, 17: 171-84.

Parra, Nicanor. 1983. Poesía política. Santiago: Bruguera.

Paz, Octavio. 1999. La otra voz, Obras completas I. Barcelona: Galaxia Gutenberg / Círculo de Lectores, $2^{\text {a }}$ edición.

Riveros, Juan Pablo. 1986. De la tierra sin fuegos. Concepción: Libros del Maitén.

Ruecker, William. 1996. "Literature and Ecology. An Experiment in Ecocriticism". The Ecocriticism Reader. Landmarks in Literary Ecology. Cheryll Glotfelty y Harold Fromm, Eds. Athens/London: University of Georgia Press, 105-23.

Sábato, Ernesto. 2000. La resistencia. Buenos Aires: Seix Barral.

Vattimo, Gianni. 1990. "El consumidor consumido", en Cuadernos de Posmodernidad, Buenos Aires.

Warwick, Fox. 1990. Toward a Transpersonal Ecology. Developing New Foundations for Environmentalism. Boston \& London: Shambhala.

Worster, Donald. 2000. Transformaciones de la Tierra: Una antología mínima de Donald Worster (selección y traducción de Guillermo Castro). Panamá: Instituto de Estudios Nacionales de la Universidad de Panamá. 